\title{
AS METÁFORAS DA CASA E DO MAR EM DOM CASMURRO
}

\section{THE METAPHORS OF THE HOUSE AND OF THE SEA IN DOM CASMURRO}

\author{
Luiz Gonzaga Marchezan*
}

RESUMO: Este trabalho estuda, em Dom Casmurro, a estratégia da narrativa de Machado de Assis em aproximar metaforicamente Bento Santiago de uma casa e Capitu do mar. Com a primeira metáfora, o autor trama um paralelo entre a alma dividida de Bento e os compartimentos de uma casa; com a segunda, aproxima os mistérios do mar aos da intimidade de Capitu.

PALAVRAS CHAVE: Realismo, Impressionismo, Ponto de vista, Metáfora.

\begin{abstract}
This paper studies Machado de Assis' narrative strategies used in Dom Casmurro to compare Bento Santiago to a house and Capitu to the sea. With the first metaphor, the author devises a parallel between Bento's divided soul and the rooms in a house. With the second metaphor, he approximates the sea mysteries to those of Capitu's intimacy.

KEY WORDS: Realism, Impressionism, Point of view, Metaphor.
\end{abstract}

* Professor Doutor da Unesp - Faculdade de Ciências e Letras, Campus de Araraquara, SP. Brasil. Email: lgmarchezan@uol.com.br. 



\section{AS METÁFORAS DA CASA E DO MAR \\ EM DOM CASMURRO}

Tristão de Ataíde (1962, p.784) observa-nos que o autor de Dom Casmurro, dado "o seu temperamento de tímido e as exigências da sua concepção da Crítica", abandonou a crítica literária sistemática, porém: "Fundiu o crítico no romancista. E deu-nos, num só planalto, a soma das duas vertentes". Voltemos nossa atenção exatamente para Dom Casmurro.

Bento Santiago representa-nos um embate entre leitor, narrador e autor: é leitor de Michel de Montaigne, de quem se aproxima, a fim de aquilatar, para suas memórias, a dicção do ponto de vista dos Ensaios. Bento Santiago, com esse propósito, faz-se protagonista e narrador de situações vividas e evocadas pelo presente da narração de Dom Casmurro. Há uma distância temporal entre o memorável e sua narração pelo romance, que o narrador quer mediar conforme a disposição abaixo:

Eu confessarei tudo o que importar à minha história. Montaigne escreveu de si: "ce ne sont pas mes gestes que jescris: c'est moi, c'est mon essence [...] Tal faço eu, à medida que me vai lembrando e convindo à construção ou reconstrução de mim mesmo." (ASSIS, 1971, p. 266).

As três últimas linhas da citação acima glosam o pensamento de Michel de Montaigne, ao que nos parece, com sua atenção voltada para a prudência do ensaísta desenvolvida nas três linhas que sucederam, em Ensaios, o 
trecho acolhido por Machado de Assis: "Devemos ser prudentes quando nos observarmos e com a mesma consciência nos apreciar quanto ao bem e quanto ao mal". (MONTAIGNE, 1972, p. 183).

Bento Santiago, narrador textual, ficcional, construído para representar, como o narrador autor de Ensaios, têm o hábito de traçar observações para os seus leitores. Michel de Montaigne (1972, p.11), na introdução dos seus Ensaios, intitulada Do autor ao leitor, pondera: "Assim, leitor, sou eu mesmo a matéria deste livro...". Ensaios manifesta, no seu texto caudaloso, o modo como uma consciência, na sua maneira assistemática de relacionar situações do domínio da subjetividade, questiona as atitudes do sujeito diante do mundo. Bento Santiago, convenhamos, não tem um comportamento tão diferente; como escritor, leitor de Montaigne e de suas memórias, escolhe e lapida metáforas; para isso, não apresenta nada eficiente, eficaz, soberano, apenas sua experiência de existir, sua educação sentimental e, assim, temos também um homem em ato, sua constituição como sujeito, sempre inconclusa.

Machado de Assis é um ficcionista, crítico e leitor que procura, de forma visível, ao menos, desde Memórias póstumas de Brás Cubas, a partir de uma intencionalidade representada no seu prefácio, um novo leitor e uma nova recepção para a literatura brasileira; quis, ao aventar por aquele novo leitor, como crítico e autor, tencionar a produção literária no tempo, tudo, num mesmo texto.

O crítico e ficcionista Machado de Assis (1962c, p. 789), já em 1858, em um ensaio intitulado "O passado, o presente e o futuro da literatura", fez um balanço da literatura brasileira e observou que carecia à ficção nacional uma "existência animada, a existência que vive, a existência que se desenvolve fecunda e progressiva", momento em que propôs aos ficcionistas atuantes, "um golpe de estado literário". Voltou à carga, em 1865, com o artigo "O ideal crítico", com o sabor da ficção e a "convicção nos lábios", momento em que apregoou como ideário para a análise da ficção: "Saber a matéria em que fala, procurar o espírito de um livro, encarná-lo, aprofundá-lo, até encontrar-lhe a alma [...]" (ASSIS, 1962a, p. 800). Em 1873, de forma menos apaixonada, escreveu no New World o seu mais incisivo ensaio: "Notícia da atual literatura brasileira - instinto de nacionalidade", em que verificou, no cenário da literatura brasileira, a ausência de um juízo crítico, sistemático, capaz de julgar a produção literária no tempo, suas formas e o gosto do seu leitor. 
Machado de Assis, dessa maneira, ao que nos parece, tem no seu ideário estético, para o horizonte do leitor da época, uma narrativa nova, plural, heterogênea; quer lhe oferecer um texto com situações vitais - conflitos, carências - dispostas em idéias que se fazem, desfazem-se, refazem-se, desdobrando-se em configurações variadas, que avançam, recuam, simulam e dissimulam. Romper com modelos tradicionais, para o crítico e ficcionista, significa trabalhar com novos procedimentos literários; dispor do material verbal, das imagens, de uma maneira tal em que transpareça uma percepção nova do objeto: uma impressão, uma sensação, no caso de Machado de Assis, e, nunca, um reconhecimento. As personagens de Machado de Assis dialogam constantemente com o presente e com o passado e a sua recordação dos fatos nunca significa a compreensão deles.

Os acontecimentos de Dom Casmurro perpassam pela mente de Bento Santiago e refletem, com conveniência, situações de lembranças, simultaneamente, da sua adolescência, juventude e maturidade. Bento, desse modo, recorda-nos como foi afetado no transcurso da sua educação sentimental e, depois, durante o seu casamento, por dúvidas e inseguranças, passadas então em revista mediante observações de seqüências infindáveis de olhares de outrem, múltiplos e entrecruzados, que tramam o romance. A história composta para esta narrativa virá com a História dos Subúrbios, proposta pelo escritor Bento Santiago no final de Dom Casmurro; este, constitui-se na trama definitiva e título provisório daquele romance inédito.

Assim, as confissões que Bento Santiago importará para dentro de suas memórias narradas serão as convenientes e essenciais à reconstrução da sua identidade, conforme a paráfrase que ele, com mediações, faz do trecho de Montaigne. Mesmo porque, a sua memória mostrar-se-á limitada: "a minha memória não é boa. Ao contrário, é comparável a alguém que tivesse vivido por hospedarias, sem guardar delas nem caras nem nomes, e somente raras circunstâncias" (ASSIS, 1971, p. 254). Além disso, já dissera: "aquela vida antiga aparece-me despida de muitos encantos que lhe achei; mas é também exato que perdeu muito espinho que a fez molesta, e, de memória, conservo alguma recordação doce e feiticeira” (ASSIS, 1971, p. 179).

A opção de Bento, como vemos, para os relatos do seu passado, faz-se por "deitar ao papel as reminiscências que me vierem vindo. Deste modo, viverei o que vivi" (ASSIS, 1971, p. 179). Bento escolhe por dar vida ao vivido, a narrar dele o que lhe foi significativo e, para isso, passa a dramatizar as sensações do que viveu a partir do que estas sensações revelam-lhe, a 
partir de uma tarde, esta sim inesquecível, do mês de novembro, do ano de 1857: data das descobertas do amor e do seu amor por Capitu, suscitadas por José Dias.

Lembremo-nos, reportando-nos, mais uma vez, ao trecho em que Michel de Montaigne é citado, que confessar o que importa é reavaliar o que a situação recordada trouxe de importante, novo e reconhecê-la como nova, desconhecida. Ocorre que, sempre enciumado, Bento reconhece, na verdade, que não consegue "recompor o que foi nem o que fui [...] mais falto eu mesmo, e esta lacuna é tudo" (ASSIS, 1971, p. 178). Isto porque o ciúme tem um motivo, uma trajetória, uma evolução, um final; o da alma de Bento Santiago não finda. O ciúme isolou Bento de Capitu, separou-os e, após a morte da amada, o estado do ciúme ainda vivido por Bento isolou-o do mundo; conferiu ao seu comportamento um traço de dor, de despeito, de receio, que o transformou num casmurro, ensimesmado, solitário, acompanhado apenas da sua imaginação, boa imaginação. É ele quem anuncia: "A imaginação foi a companheira de toda a minha existência, viva, rápida, inquieta, alguma vez tímida e amiga de empacar, as mais delas capaz de engolir campanhas e campanhas, correndo" (ASSIS, 1971, p. 231).

Bento Santiago, dominado pelo comportamento do ciúme, tende a exagerar tudo o que cogita. Nos momentos em que alia o seu comportamento enciumado à imaginação, exacerba-a e compromete suas campanhas, $o$ conjunto de suas ações. Bento, casmurro, procura conscientizar-se de tudo o que ocorreu na sua vida diante de Capitu. Da meninice ao namoro, do namoro ao casamento, do casamento à separação. O narrador de Dom Casmurro, depois de 40 anos, rememora a sua vida e procura sua consciência; procura a identificação de determinados acontecimentos com determinados comportamentos, a fim de delimitar, isso sim, no bojo dessa questão, a sua individualidade e, daí, estabelecer um conceito de si mesmo. Bento Santiago questiona a sua identidade. A identidade é pensante, aberta. Desse modo, o Bento adulto, sofrido, consciente do seu sofrimento, corroído pelo ciúme, identificado com a dor, questiona o Bentinho sem identidade, criado entre três viúvos e um assexuado. Entre o menino e o adulto, uma história suburbana, e uma trama, esta, por meio das observações de um casmurro confesso.

O romancista da História dos subúrbios, de forma excessiva, açula a memória dos acontecimentos, fragmenta-a no tempo e no espaço e, de uma maneira a menos realista possível, opta por uma narrativa em primeira 
pessoa, tensa, que, inegavelmente, recai numa individualidade, no caso, na figura do narrador autodiegético. Quem sou eu, questiona-se, a todo momento, Bento Santiago, sempre envolvido com a questão da sua identidade. Bento quer avaliar a sua identidade para avaliar a sua vida. $O$ valor é a medida do mundo. Machado de Assis, por sua vez, não libera verdades, valores aparentes; ele gosta de metáforas, de paralelos; prefere a plurissignificação.

O foco narrativo é uma perspectiva da enunciação, o modo como a enunciação constrói sua estratégia de representação, a configuração discursiva da história. $\mathrm{O}$ foco narrativo trabalha com a quantidade e qualidade de informações veiculadas dentro de uma narrativa. A enunciação, por meio do foco narrativo, delega a um narrador, voz para a narração. Nessa voz ouvimos a atitude valorativa do narrador: emoções, reações que (objetiva ou subjetivamente), ficam cristalizadas em imagens. O foco narrativo operacionaliza, para a enunciação, o que ela quer fazer ver e como ela quer fazer ver. Um ponto de vista combina e dá seguimento para uma história, ao mesmo tempo em que a configura. Combinações e seqüências constroem e movimentam, tramam uma história.

José Dias foi quem despertou a imaginação de Bento Santiago e, enquanto viveu, foi o seu confidente. Bento, o casmurro, chorou no dia da sua morte. José Dias, em vida, sempre foi atrevido, porém, suas ousadias nunca incorreram quer em riscos, quer em desacertos, medidas procuradas constantemente pelo seu aprendiz. Ao lado disso, e isso é tudo, o preceptor de Bento Santiago, como dissemos, despertou-lhe para o amor e para o único grande amor da vida de Dom Casmurro, ensinando-lhe, ao lado desta revelação, a observar, de forma imaginosa, olhares. O bom aluno de José Dias é quem, certa feita, pensou: "A recordação de uns simples olhos basta para fixar outros que o recordem e se deleitem com a imaginação deles". (ASSIS, 1971, p. 307). Dom Casmurro tornou-se um observador obsessivo de olhares. Desta maneira, para o romance que pretende escrever, o olhar arquiteta conflitos, ao mesmo tempo em que passa a ser uma forma de fixação do narrador e observador Bento Santiago, que, ao espreitar o observado, transforma-o em objeto da sua compulsão.

O olhar, em Dom Casmurro, representa as sensações do observador Bento Santiago; consiste num processo, numa marcha, na própria busca, por meio de sensações, da identificação do protagonista consigo e com os outros. Os circuitos do olhar exprimem, no romance, uma atitude cognitiva; manifestam o saber atribuído aos seus sujeitos instalados no discurso. Tais 
saberes constituem-se em estados, sensações, revelados pelos olhos "dorminhocos" (passivos) de Tio Cosme; "redondos" (práticos), de Pedro de Albuquerque, pai de Bento; "aéreos" (fúteis), de Pádua, pai de Capitu, ou, por meio dos olhos "curiosos" de prima Justina; "claros e inquietos" de Ezequiel; "quentes e intimativos" de Sancha; por intermédio dos olhos de José Dias, "esbugalhados, escancarados" (observadores de tudo e de todos, portanto), ou, ainda, através das ações dos olhos de Escobar, "claros, fugitivos, enfiados em si", cogitando; "refletidos", segundo a observação de Tio Cosme; "policiais", na observação de prima Justina.

Os olhares, em Dom Casmurro, a partir da sua observação pelo narrador, dão-nos o modo da ação da narrativa; eles exercem a sobredeterminação da narrativa, envolvendo-a em saberes contidos em sensações que, uma vez por eles atravessadas, cintilam. Temos, assim, uma narrativa motivada por estados, atmosferas e sem rupturas, sem a quebra de continuidade, o que nos leva a deduzir que não há o interesse por parte do enunciador em construir um ponto de vista de certeza; há interesse sim na construção de uma dúvida. Os olhares, em Dom Casmurro, têm um saber que, de forma subliminar, expressam o modo do querer das personagens; constituem o percurso figurativo do seu querer; representam o sentido da busca da narrativa de Bento Santiago, confiada aos seus desejos e saberes. Estes olhares são simulacros, imagens de recordações, recordações respeitadas. Respeitar, do ponto de vista etimológico, significa olhar muitas vezes para trás. Bento Santiago respeita as sensações que repassam pela sua memória, expandidas em olhares diversos, apreendidos pelos seus olhares "constantes, longos", que observam olhos e olhares de todos. Bento aprendeu com os olhos "curiosos" de prima Justina, "escancarados" de José Dias; assustou-se, atrapalhou-se e depois delirou diante dos olhos "inquietos" de Ezequiel; incomodou-se com os olhos "quentes e intimativos" de Sancha; atrapalhou-se com os olhos dos quais não escapa nada, "policiais", de Escobar; perdeu-se e foi tragado pelos de Capitu.

Os olhares de todos os notados espelham, enfim, um querer. Os do narrador, observadores, dão acabamento às sensações que o protagonista quer filtrar por intermédio dos olhares alheios. Bento Santiago procura, por meio dessas observações, uma percepção de todos, com marcas de verdades.

Os olhares de Capitu, de acordo com o narrador, camuflam, dissimulam, porque querem dissimular o seu ser. É o que atormenta Bento, o que embaraça a sua atividade interpretativa. Os olhos de Capitu são olhos claros 
e grandes, fitam-se e desfitam-se; crescem e diminuem; apertam-se, espreitam, voltam-se para dentro, arrastam. Dessa maneira, dentro do romance, os olhos de Bento simulam a prática do olhar de todos, com o propósito de elaborar para ele, o observador, o saber de todos; os de Capitu, dissimulam. Assim, o ser, o caráter dessa personagem, fica submerso num emaranhado de aparências, num jogo entre sensações. É importante observarmos como a ação do olhar de Capitu cria no narrador observador, sensações, quase percepções, porém, de forma segura, jamais reconhecimentos. Divide-o também. Bento Santiago encontra-se sempre dividido, compartimentado, diante do seu mundo sensível.

Bento Santiago é quem reproduz no Engenho Novo a mesma casa da infância, a da Rua Matacavalos e reconhece que, com tal empreita, não conseguiu "recompor o que foi nem o que fui. Em tudo, se o rosto é igual, a fisionomia é diferente" (ASSIS, 1971, p. 178). O mesmo Bento, dividido, repartido, que releva metáforas, comenta: "A alma da gente, como sabes, é uma casa assim disposta, não raro com janelas para todos os lados [...]" (ASSIS, 1971, p. 251).

O perfil do narrador, diviso, assemelha-se com a divisão interna de uma casa. A metáfora da casa lê a intimidade de Bento Santiago. O que move o julgamento de Bento Santiago, sempre pouco vigoroso, é querer constantemente saber se a Capitu (da casa) de Matacavalos é a Capitu (da casa) da praia da Glória. A passagem que nos exemplifica de forma cabal o Bento Santiago que descrevemos está no capítulo 133: "Uma idéia". Bento Santiago, visivelmente transtornado, tem uma idéia para o término do seu sofrimento - suicídio por envenenamento. Nesse dia, a maneira como Machado de Assis aproxima seu protagonista da metáfora da casa é emblemática:

Fui à casa de minha mãe, com o fim de despedir-me, a título de visita. Ou de verdade ou por ilusão, tudo ali me pareceu melhor nesse dia, minha mãe menos triste, tio Cosme esquecido do coração, prima Justina da língua. Passei uma hora em paz. Cheguei a abrir mão do projeto. Que era preciso para viver? Nunca mais deixar aquela casa, ou prender aquela hora a mim mesmo [...]. (ASSIS, 1971, p. 333-334).

O mesmo Bento dividido, compartimentado, releva metáforas e é tragado pelos olhos de ressaca de Capitu; observando-os, faz um paralelo entre os mistérios presentes para ele nos olhos da amada com os ritmos da vaga 
(composição de elevações da superfície da água; elevações que se propagam umas às outras, produzidas, em geral, pela ação do vento), do mar em ressaca. Os olhos de Capitu, confessa Bento: "traziam não sei que fluido misterioso e enérgico, uma força que arrastava para dentro, como a vaga que se retira da praia, nos dias de ressaca" (ASSIS, 1971, p. 219). Capitu é misteriosa como o mar. Tem os mistérios do mar. Dissimula como a vaga do mar. O mar, com seus mistérios, é símbolo da dinâmica da vida. Bento não é dinâmico, é estático, "homem de terra" (ASSIS, 1971, p. 332), conforme sua auto-análise. As metáforas - mar e terra - representam o conflito entre os amantes.

O enredo de Dom Casmurro é difuso, motivado por recordações intrincadas que aproximam o homem do menino, sem que o Bento adulto tenha uma idéia acabada acerca do que narra a partir da sua meninice. Machado de Assis, assim, afasta-se do romance de tese, realista, naturalista; voltase para a realidade humana, considerada em Dom Casmurro por um viés impressionista. Machado de Assis trabalha este romance com impressões, atmosferas compartilhadas entre as personagens que participam de uma mesma trama; ocupa-se, precisamente, com sensações. A fim de confrontar individualidades, identidades, ele aproxima Capitu do mar e Bento da casa e, na ausência de verdades aparentes, de argumentos, as impressões, as sensações é que estabelecem um juízo de valor. O procedimento da metáfora, como sabemos, é o de eliminar diferenças entre as diferentes realidades conotadas, aproximando-as. Machado de Assis joga com metáforas: Bento Santiago é tão compartimentado como uma casa e, mais, aos compartimentos de sua casa materna; Capitu dissimula como a vaga do mar.

O papel do narrador e protagonista Bento Santiago, assim, faz-se o de, ao querer refletir sobre o que viu, construir, indiretamente, imagens por meio de olhares, pautando-se pelas da casa e do mar, as mais sensíveis e transfiguradoras metáforas do romance. As sensações narradas sempre compõem estranhamentos e perfazem uma distância larga entre o vivido, estranho, sua absorção e a atmosfera surgida no âmbito da sua retenção.

Machado de Assis (1962e, p. 908), como dissemos, afasta-se da narrativa realista, de tese. $\mathrm{Na}$ análise que fez, em 1878, d'O primo Basílio, de Eça de Queiroz, tal posicionamento tornou-se evidente: "o perigo do movimento realista é haver quem suponha que o traço grosso é o traço exato". O diagnóstico cabal que Machado de Assis (1962e, p. 913), faz do Realismo, cremos, está no trecho abaixo, do mesmo artigo acima citado: "esse messianismo 
literário não tem a força da universalidade nem da vitalidade; traz consigo a decrepitude [...] Voltemos os olhos para a realidade, mas excluamos o Realismo, assim não sacrificaremos a verdade estética”.

O autor de Dom Casmurro retrata sensações, atmosferas, resultantes, no âmbito da narrativa, do vivido, absorvido e que motivam as sensações deflagradas pelas personagens mediante o que viveram e experimentaram. O criador de Bento Santiago é impressionista, queremos enfatizar. Impressionismo é a expressão indireta de um significado. A impressão é decorrente de um conjunto de fatores ligado ao acontecimento narrado e, por isso, deflagra sensações. As sensações nos dão as disposições, as condições que se associam ao acontecimento narrado e trabalham os efeitos de sentido dessas qualidades sobre nós.

Bento Santiago procurou livrar-se de suas ruínas interiores demolindo a casa materna; ao reconstruí-la, no Engenho Novo, nos moldes da primeira, não conseguiu livrar-se dos seus escombros.

Em uma caminhada com José Dias, pelo Passeio Público, Bentinho é despertado para a profundidade contida nos olhos de Capitu. Durante o passeio, no percurso do portão central até o terraço, José Dias, pela primeira e fatídica vez, qualifica os olhos de Capitu: oblíquos, dissimulados, de cigana. Bentinho ficará com o traço da dissimulação notado por José Dias; acrescentará, porém, ao seu modo de caracterizar os olhos da amada, os traços da ressaca do mar. O terraço do Passeio Público, no tempo da produção de Dom Casmurro, fazia divisa com o mar; posteriormente, a baia foi aterrada e o terraço distanciou-se do mar. O juízo de José Dias sobre os olhos de Capitu deu-se diante do mar, sem incluí-lo na sua metáfora, enquanto conversava com o seu aprendiz. Em sua ponderação sobre os olhos de Capitu, noutro momento, distante da praia e do episódio, Bentinho somou à metáfora elaborada pelo agregado, então no Passeio, diante do mar, a dele, firmada a partir do mar. Machado de Assis, de fato, distanciava-se do Realismo; foi um sensacionista, impressionista, movido por impressões, construtor de impressões.

Henry James (1995, p. 32), em A arte da ficção, ensaio de 1884, escreve que: "Um romance é uma coisa viva, e à medida que ele vive será visto, creio, que em cada uma de suas partes há alguma coisa das outras". Eugênio Gomes (1962, p. 1098), quando escreve "O testamento estético de Machado de Assis”, observa, em Dom Casmurro, nos moldes da citação que fizemos do texto de James, que "o romancista conseguiu fazer desse romance o mais 
orgânico e vital de todos os que escreveu". Ou, conforme o seu narrador: "o discurso humano é assim mesmo, um composto de partes excessivas e partes diminutas, que se compensam, ajustando-se" (ASSIS, 1971, p. 258). Em Dom Casmurro, concluímos nós, tanto as personagens, como nós, leitores, ficamos transitando entre as sensações, as aparências, conjugadas, sem rupturas, na narrativa, pelo jogo das modalidades ser e parecer. Nele, o seu autor, Machado de Assis, cremos, sempre crítico, exercita a sua ficção depois de concluir as suas reflexões em torno de uma teoria da alma humana. Machado de Assis, com Dom Casmurro, está voltado para a história de um indivíduo que procura a sua identidade. Com esse romance, deixa as inquietudes universais para debater as individuais.

Machado de Assis (1971, p. 179), em Dom Casmurro, está voltado para uma impressão da vida, a impressão de Bento Santiago sobre a sua vida: "comecemos a evocação por uma célebre tarde de novembro, que nunca me esqueceu. Tive muitas outras, melhores e piores, mas aquela nunca se me apagou do espírito".

Evocar é fazer aparecer, trazer à lembrança, no caso, algo do passado, "uma célebre tarde de novembro". A evocação é um recurso retórico de atenuação, que nos coloca, diante da leitura do romance, entre o conteúdo da expressão que se pretendeu enunciar de forma dissimulada, metaforizada e o conteúdo da expressão que se pretendeu enunciar de forma simulada, evocada, deixando o texto envolto em aparências e nas malhas do imaginário do romance. Uma evocação dá plena vazão aos impressionismos e, com isso, Machado de Assis elabora umas das mais belas impressões literárias da vida depois do golpe literário que propôs em 1858. Quando pensou o homem em Memórias póstumas de Brás Cubas, definiu-o, inspirado em Blaise Pascal, como uma "errata pensante". Naquele romance, Cubas, pensando por todos os homens, reflete que podemos: "restaurar o passado, para tocar a instabilidade de nossas impressões e a vaidade dos nossos afetos" (ASSIS, 1962b, p. 547). Em Dom Casmurro, o autor trabalha com a intimidade de um homem, Bento Santiago, que revê, mas não consegue montar a edição definitiva da história dos seus afetos. Bento Santiago é afetado, frágil, dono de uma "incorrigível timidez" (ASSIS, 1971, p. 268). Bento Santiago é compartimentado e quanto mais procura definir no tempo a sua identidade, percebe que, para esta definição "mais falto eu mesmo, e esta lacuna é tudo" (ASSIS, 1971, p. 178).

As observações de Blaise Pascal (1973, p. 127) utilizadas por Machado 
de Assis em Memórias póstumas de Brás Cubas constam do artigo VI, item 347, primeiro parágrafo dos seus Pensamentos: "O homem não passa de um caniço, o mais fraco da natureza, mas é um caniço pensante". Constitui o mesmo item, no seu segundo parágrafo: "Toda a nossa dignidade consiste, pois, no pensamento. Daí é que é preciso nos elevarmos, e não do espaço e da duração, que não poderíamos preencher. Trabalhemos, pois, para bem pensar; eis o princípio da moral". No item seguinte, o 348, do mesmo artigo VI, mais especificamente, teremos: "Não é no espaço que devo buscar minha dignidade, mas na ordenação de meu pensamento". Blaise Pascal raciocina com emoção; o narrador e personagem de Machado de Assis de Dom Casmurro dosa a sua emoção para pensar e, assim, dá-nos um pensamento no limite da sua exposição. Blaise Pascal (1973, p. 540), é leitor de Michel Montaigne:

Não é em Montaigne, mas em mim mesmo, que acho tudo o que nele vejo [...] É preciso conhecer-se a si mesmo; se isso não servisse para encontrar a verdade, serviria ao menos para regular a vida, e não há nada mais justo.

Machado de Assis é leitor de Blaise Pascal e de Michel de Montaigne; como ficcionista, fez também seus leitores os seus narradores Cubas e Bento, por seu turno, dois escritores memorialistas. Ambos, como romancistas e, pela memória, em suas narrativas, procuram analisar, por princípios morais, o que não viveram. O primeiro, com a morte, libertou-se do embate justo com a verdade; a prudência limitou o senso da memória de Bento, que, com o pensamento temeroso, elaborado a partir de uma passagem que destacamos dos Ensaios, não ousou, como Pascal - a partir do pensamento ordenado no tempo e não da sua ordenação no espaço - a enfrentar os escritos de Montaigne, com coragem e discernimento.

Bachelard (1978, p. 227) mostra-nos que o espaço é o lugar de defesa do sujeito, que nele explicita o que estranha do mundo, momento em que se defende. Bento Santiago, certa feita, com um ímpeto de suicídio, encaminha-se para a casa materna:

Fui à casa de minha mãe, com o fim de despedir-me, a título de visita. Ou de verdade ou por ilusão, tudo ali me pareceu melhor nesse dia, minha mãe menos triste, tio Cosme esquecido do coração, prima Justina da língua. Passei uma hora de paz. Cheguei a abrir mão do projeto. Que era 
preciso para viver? Nunca mais deixar aquela casa, ou prender aquela hora a mim mesmo [...] (ASSIS, 1971, p. 334).

Bento Santiago, inegavelmente, sempre teve dificuldade para lidar com sua existência. A casa de Matacavalos, para ficarmos novamente com Bachelard (1978, p. 227), foi o seu reduto, lugar de resistência contra as mudanças provocadas pela vida, as controvérsias do tempo, o que tão bem lemos noutra situação, também adversa, quando o narrador e personagem visita o jardim daquela casa, após a morte da mãe:

Hão de perguntar-me por que razão, tendo a própria casa velha, na mesma rua antiga, não impedi que a demolissem e vim reproduzi-la nesta. A pergunta devia ser feita a princípio, mas aqui vai a resposta. A razão é que, logo que minha mãe morreu, querendo ir para lá, fiz primeiro uma longa visita de inspeção por alguns dias, e toda a casa me desconheceu. No quintal, a aroeira e a pitangueira, o poço, a caçamba velha e o lavadouro, nada sabia de mim. A casuarina era a mesma que eu deixara ao fundo, mas o tronco, em vez de reto, como outrora, tinha agora um ar de ponto de interrogação; naturalmente pasmava intruso. Corri os olhos pelo ar, buscando algum pensamento que ali deixasse, e não achei nenhum. Ao contrário, a ramagem começou a sussurrar alguma coisa que não entendi logo, e parece que era a cantiga das manhãs novas. Ao pé dessa música sonora e jovial, ouvi também o grunhir dos porcos, espécie de troça concentrada e filosófica.

Tudo me era estranho e adverso. Deixei que demolissem a casa, e, mais tarde, quando vim para o Engenho Novo, lembrou-me fazer esta reprodução por explicações que dei ao arquiteto, segundo contei em tempo. (ASSIS, 1971, p. 342).

A morte de dona Glória sitiou o filho no espaço e no tempo. Na passagem acima lemos como, sem a mãe, a casa materna fixa-lhe as referências do tempo no espaço, as do reduto de Bento Santiago, que ora não percebe, com discernimento, que parte muito significativa da sua vida mudou, como para ele o seu quintal e, assim, sentindo-se quase humilhado com o grunhido dos porcos - uma troça filosófica - como nota, manda demolir a casa de Matacavalos.

A inventiva de Bento em reconstruir, no Engenho Novo, a casa materna, compreende, como ele confessa, a "construção ou reconstrução de mim mesmo" (ASSIS, 1971, p. 266), uma empreitada decidida, que se concretiza apenas fisicamente. Mostra-nos o texto que, defronte do término da sua 
evocação e ante à incapacidade de superar as dúvidas que lhe dilaceram a alma, a moradia da sua infância, na Matacavalos, transforma-se, no Engenho Novo, numa "caverna" (ASSIS, 1971, p. 177), outra, diríamos, troça filosófica. Bento Santiago, dessa maneira, direciona a sua alma para um abrigo subterrâneo, certificando-se, ao menos, como "homem de terra" (ASSIS, 1971, p. 332), de alma subterrânea e evita, em mais um reduto, que sua alma, irremediavelmente perdida, vague pelos cômodos já muito conhecidos da planta da sua casa materna. A metáfora da casa, na semelhança entre os seus compartimentos com os da alma humana, mais uma vez, traduziu para o protagonista sua incapacidade em lidar com o tempo vivido. O lugar da alma de Bento Santiago, uma alma arruinada, é numa ruína, uma caverna.

No seu penúltimo livro, Relíquias da casa velha, de 1906, notamos Machado de Assis (1962d, p. 658), ainda visceralmente envolvido com a metáfora da casa. Logo na Advertência lemos:

Uma casa tem, muita vez, as suas relíquias, lembrança de um dia ou de outro, da tristeza que passou, da felicidade que se perdeu. Supõe que o dono pense em as arejar e expor para teu o meu desenfado [...] Chama-lhe à minha vida uma casa.

À minha vida é um aposto de lhe, tem a mesma função dativa de lhe; quer dizer: chame a ela, minha vida, uma casa. A construção meticulosa da personagem Bento Santiago, certamente, está habilitada pelo arquiteto dessa advertência.

\section{Referências Bibliográficas}

ASSIS, Machado de. O ideal crítico. In: ___ . Obras completas. Rio de Janeiro: Ed. José Aguilar, 1962a., v.3, p. 798-801.

ASSIS, Machado de. Memórias póstumas de Braz Cubas. Rio de Janeiro: Ed. José Aguilar, 1962. In: Obras completas. Rio de Janeiro: Ed. José Aguilar, 1962b., v.1, p. 508-637.

ASSIS, Machado de. O passado, o presente e o futuro da literatura. In: . Obras completas. Rio de Janeiro: Ed. José Aguilar, 1962c., v. 3, p. 785-789. 
ASSIS, Machado de. Relíquias da casa velha. In: Obras completas. Rio de Janeiro: Ed. José Aguilar, 1962d., v.1, p. 557-733.

ASSIS, Machado de. Eça Queiroz: O Primo Basílio. In: ASSIS, Machado de. Obras completas. Rio de Janeiro: Ed. José Aguilar, 1962e., v. 3, p. 903-913. ASSIS, Machado de. Dom Casmurro. São Paulo: Ed. Abril, 1971. ATAIIDE, Tristão de. Machado de Assis, o crítico. In: ASSIS, Machado de. Obras completas. Rio de Janeiro: Ed. José Aguilar, 1962, v. 3, p. 779-784.

BACHELARD, G. A poética do espaço. São Paulo: Ed. Abril, 1978. (Os pensadores).

GOMES, E. O testamento estético de Machado de Assis. In: ASSIS, Machado de. Obras completas. Rio de Janeiro: Aguilar, 1962, v. 3, p. 1096-1120. JAMES, H. A arte da ficção. São Paulo: Imaginário, 1995.

MONTAIGNE, M. Ensaios. São Paulo: Ed. Abril, 1972. (Os pensadores).

PASCAL, B. Pensamentos. São Paulo: Ed. Abril, 1973. (Os pensadores). 